\title{
Molecular biology of squamous cell carcinoma of the head and neck
}

\author{
B Perez-Ordoñez, M Beauchemin, R C K Jordan
}

J Clin Pathol 2006;59:445-453. doi: 10.1136/icp.2003.007641

Squamous cell carcinoma of the head and neck (HNSCC) is a heterogeneous but largely preventable disease with complex molecular abnormalities. It arises from a premalignant progenitor followed by outgrowth of clonal populations associated with cumulative genetic alterations and phenotypic progression to invasive malignancy. These genetic alterations result in inactivation of multiple tumour suppressor genes and activation of proto-oncogenes, including p16 ${ }^{\text {ink4A }}, \mathrm{p} 53$, cyclin D1, p14 ${ }^{\mathrm{ARF}}$, FHIT, RASSFIA, epidermal growth factor receptor (EGFR), and $\mathrm{Rb}$. Intramucosal migration and clonal expansion of transformed cells with formation of abnormal genetic fields appear to be responsible for local recurrences and development of second primary tumours.

See end of article for authors' affiliations ......................

Correspondence to: Dr Bayardo PerezOrdoñez, Department of Pathology, University Health Network, Princess Margaret Hospital, 610 University Avenue, Toronto, Ontario M4N 3M5, Canada; bayardo. perez-ordonez@uhn.on.ca
$\mathrm{S}$ quamous cell carcinoma of the head and neck (HNSCC) remains a significant cause of morbidity and mortality, with approximately 540000 new cases annually worldwide and 271000 deaths for a mortality of $50 \% .^{1}$ An estimated 4350 new cases of oral and laryngeal carcinoma are diagnosed each year in Canada, with 1560 tumour related deaths giving a mortality of $36 \% .^{2}$ In the USA, the use of adjuvant radiotherapy after surgery, and concurrent chemotherapy and radiotherapy, has resulted in improved five year survival rates for advanced carcinomas of the larynx and pharynx but no survival improvement has been seen for oral carcinomas and early laryngeal carcinomas. ${ }^{3}$ Conventional HNSCC is largely a preventable disease. Major risks factors include tobacco use and alcohol consumption in developed countries and betel quid chewing and bidi smoking in Southeast Asia. The past decade has witnessed significant progress in the understanding of the molecular genetic events underlying the development of HNSCC. ${ }^{4-6}$ The promise of these studies is the development of novel diagnostic and therapeutic procedures which can be used in the clinical management of these patients. ${ }^{7}$

HNSCC is a heterogeneous disease with complex molecular abnormalities. In this review we attempt to summarise the molecular mechanisms underlying certain clinicopathological characteristics of squamous neoplasia in the head and neck observed by surgical pathologists. Our goal is to highlight some of the advances made in the understanding of the molecular progression from dysplasia to invasive carcinoma, and the role played by molecular alterations found in non-neoplastic mucosa of patients with HNSCC in local tumour recurrences and the development of second primary HNSCCs. We also survey recent progress in the molecular classification of HNSCC provided by genomic arrays, the molecular biology of HNSCC in "young" individuals, and the relation of human papillomavirus (HPV) and HNSCC.

\section{MOLECULAR PATHOLOGY AND TUMOUR PROGRESSION}

Genetic alterations and progression of squamous dysplasia to invasive carcinoma It is generally accepted that HNSCC arises from a common premalignant progenitor followed by outgrowth of clonal populations associated with cumulative genetic alterations and phenotypic progression to invasive malignancy. ${ }^{8-10}$ These genetic alterations result in inactivation of tumour suppressor genes and activation of proto-oncogenes by deletions, point mutations, promoter methylation, and gene amplification (table 1). Microsatellite marker analysis has allowed the delineation of a genetic progression model for HNSCC based on the frequency of these genetic alterations in preinvasive lesions and invasive tumours (fig 1). ${ }^{910}$ Loss of chromosomal region $9 \mathrm{p} 21$ is found in $70-80 \%$ of cases, thus representing the most common genetic alteration seen in squamous dysplasia and HNSCC. ${ }^{11} 12$ Loss of heterozygosity ( $\mathrm{LOH}$ ) of 9p21 appears to be an early event in squamous neoplasia of the head and neck and has been found in preneoplastic lesions, including 30\% of cases of squamous hyperplasia. ${ }^{11-13}$ The CDKN2A gene locus found in chromosome 9p21 encodes two different transcripts, p16 and p14 ${ }^{\mathrm{ARF}}$, which are responsible for $G_{1}$ cell cycle regulation and MDM2 mediated degradation of p53. P16 is often inactivated in HNSCC through homozygous deletion, by promoter methylation, and less commonly by point mutations. ${ }^{14}$

Loss of chromosome region $3 p$ is another common early genetic event in squamous dysplasias and invasive HNSCC. ${ }^{15-17}$ The specific locus responsible for the tumour suppressor phenotype of $3 \mathrm{p}$ remains uncharacterised but investigators have identified at least four distinct regions of allelic loss. ${ }^{15} 18$ These regions include 3p14, 3p21, 3p22, 3p24, and 3p26. 3p14 contains the fragile histidine triad gene or FIHT, a putative tumour suppressor gene, which has been found

Abbreviations: CIS, carcinoma in situ; HNSCC, squamous cell carcinoma of the head and neck; HPV human papillomavirus; LOH, loss of heterozygosity; SPT, second primary tumour 


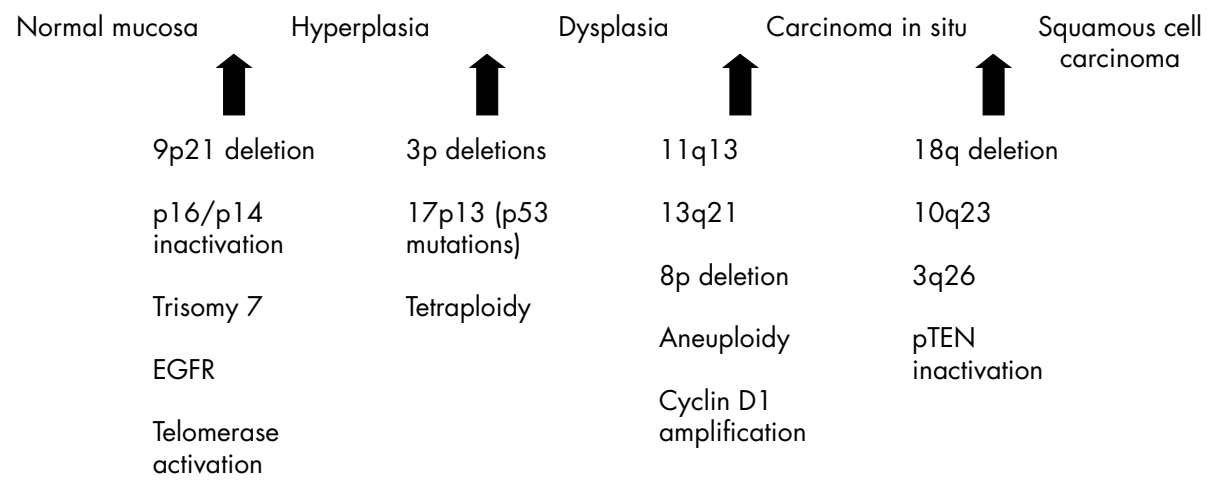

Figure 1 Hypothetical model for HNSCC carcinogenesis, modified from Califano et al. ${ }^{9}$

to be inactivated by exonic deletions in many tumour types including a small percentage of HNSCC. ${ }^{19}{ }^{20}$ RSSF $1 A$ is another candidate tumour suppressor gene mapped to $3 \mathrm{p} 21$ and found to be inactivated by hypermethylation in a small subset of HNSCC. ${ }^{16}{ }^{21}$ Much controversy remains regarding the genes present in $3 \mathrm{p}$ and their significance and possible roles in HNSCC carcinogenesis. Thus therefore further studies continue.

$\mathrm{LOH}$ of $17 \mathrm{p}$ and point mutations of the p53 are seen in approximately $50 \%$ of HNSCC cases. $^{822}$ Most of these mutations appear to occur late in the progression from epithelial dysplasia to invasive carcinoma. ${ }^{23}{ }^{24}$ In a study including 102 invasive carcinomas, 13 severe dysplasias, and 24 cases of squamous carcinoma in situ (CIS), Boyle et al ${ }^{23}$ reported a prevalence of p53 mutations in $43 \%$ of the invasive carcinomas and $19 \%$ in the non-invasive lesions. In a longitudinal study of 10 patients with sequential biopsies showing progression from hyperplasia or mild dysplasia to CIS or invasive carcinoma, Shahnavaz et $a^{24}$ identified p53 mutations in one of 12 dysplasias (8\%), two of three CIS cases $(66 \%)$, and six of eight invasive carcinomas $(75 \%)$. Nearly $64 \%$ of p53 mutations in HNSCC occur in G nucleotides, consistent with exposure to carcinogens such as tobacco. ${ }^{23}$

Amplification of $11 \mathrm{q13}$ and overexpression of cyclin D1 is seen in $30-60 \%$ of HNSCC cases and has been associated with an increased rate of lymph node metastases and overall poor prognosis. ${ }^{25-27}$ Cyclin DI induces phosphorylation of Rb, thus enabling progression from $G_{1}$ to $S$ phase. Both amplification of cyclin DI and inactivation of pl6 result in increased phosphorylation of $\mathrm{Rb}$ and progression in the cell cycle from $\mathrm{G}_{1}$ to $\mathrm{S}$ phase. Amplification and overexpression of cyclin DI has been described in up to $40 \%$ of cases of oral squamous dysplasia, including mild dysplasia. ${ }^{28}$

In contrast to some colorectal carcinomas, where microsatellite instability is common, in HNSCC this alteration has been identified in only a small subset of preinvasive lesions of the head and neck. ${ }^{29}$ El-Naggar et al ${ }^{29}$ reported it in $15 \%$ of a

Table 1 Frequent molecular abnormalities in head and neck squamous cell carcinoma

\begin{tabular}{ll}
\hline LOH 9p & $70-80 \%$ \\
LOH 3p & $60-70 \%$ \\
LOH 17p & $50-70 \%$ \\
LOH 11q & $30 \%$ \\
LOH 13q & $30 \%$ \\
Inactivation of pl6 $6^{\text {ink4A }}$ (homozygous deletion, promoter & $80 \%$ \\
methylation, point mutation) & $50-80 \%$ \\
Inactivation of FHIT and RASSF1A p53 mutation & $30 \%$ \\
Cyclin D1 amplification & \\
\hline
\end{tabular}

small group of head and neck dysplasias. In another study, Ha and coworkers $^{30}$ showed that it becomes increasingly more common as dysplastic lesions progress to HNSCCs.

Gene expression microarrays suggest that most of transcriptional alterations in head and neck carcinogenesis occur during the transition from normal mucosa to premalignant lesions rather than in the transformation from premalignant lesion to invasive carcinoma. ${ }^{31}$ When compared with normal mucosa, premalignant lesions showed 108 upregulated and 226 downregulated genes, whereas invasive carcinomas had five upregulated and 13 downregulated genes when compared with premalignant lesions. ${ }^{31}$

\section{Genetic alterations and risk of progression to malignancy}

Leukoplakia and erythroplakia have a well documented risk for transformation into HNSCCs. ${ }^{32}{ }^{33}$ The risk of malignant transformation increases with the microscopic finding of dysplasia; however, there is significant lack of agreement in the grading of oral dysplasias. ${ }^{34}$ One of the promises offered by a better understanding of the molecular basis of preneoplastic lesions of the head and neck is the provision of ancillary tools to provide objective and reproducible grading and estimation of risk of evolving to invasive carcinoma. Oral premalignant tissues frequently show many genomic alterations. In a study by Mao et al, ${ }^{12} 51 \%$ of patients whose lesions were investigated for $\mathrm{LOH}$ at $9 \mathrm{p} 21$ and $3 \mathrm{p} 14$ loci showed allelic loses at either or both loci. Of the 19 patients with LOH, seven (37\%) developed HNSCC while only one of 18 patients without LOH developed HNSCC. In another study of patients with oral leukoplakia, three biomarkers-chromosomal polysomy, suprabasal p53 expression, and $\mathrm{LOH}$ at chromosome $3 \mathrm{p}$ or $9 \mathrm{p}$-were found to be the most significant predictors of invasive cancer development, in addition to the presence of moderate/severe dysplasia and a past history of oral cancer. ${ }^{35}$ Rosin and collaborators ${ }^{13}$ showed differing LOH patterns between nonprogressing and progressing low grade oral dysplasias. Both types of lesion were characterised by $\mathrm{LOH}$ at $3 p$ or $9 p$ or both; however, patients with progression to in situ or invasive squamous cell carcinomas showed additional losses on $4 \mathrm{q}$, $8 \mathrm{p}, 11 \mathrm{q}$, or $17 \mathrm{p}$. The same group of investigators have shown that toluidine blue staining identifies premalignant lesions with "high risk" LOH patterns associated with the development of invasive HNSCC. ${ }^{36}$

Evaluation of DNA ploidy in oral leukoplakia allows the identification of gross genomic alterations and has been show to be a useful tool in identifying lesions with a high risk of malignant transformation. ${ }^{37}{ }^{38}$ Sudbø et $a l^{37}$ studied the lesional DNA content in 150 patients with oral leukoplakia and epithelial dysplasia. Thirty six (24\%) developed a carcinoma after a mean follow up of 49 months; however, 
only three of 105 diploid cases (3\%) develop invasive disease, as compared with 21 of 25 aneuploid cases (84\%) and 12 of 20 tetraploid cases $(60 \%)$. The negative predictive value for diploid lesions was $97 \%$ and the positive predictive value for aneuploid lesions was $84 \%$. DNA content appeared to be an independent prognostic factor, with no statistically significant correlation with the grade of dysplasia. In an earlier study, the same investigators analysed ploidy status of 45 leukoplakic lesions histopathologically negative for dysplasia. ${ }^{38}$ Thirty five lesions (78\%) were diploid, five (11\%) were tetraploid, and five $(11 \%)$ were aneuploid. Four of the five aneuploid cases developed carcinoma $(80 \%)$ whereas only one of the diploid/tetraploid cases $(2 \%)$ developed malignancy. ${ }^{38}$ Patients with aneuploid leukoplakia have a $98 \%$ rate of developing primary oral carcinoma, an $81 \%$ rate of recurrent or second primary tumours, and a $76 \%$ risk of death from disease despite negative histology of the surgical margins. ${ }^{39}$ Thus ploidy status, chromosome polysomy, and $\mathrm{LOH}$ analysis of oral precancerous lesions may provide important information about the risk of progression to cancer, second cancer development, and tumour specific death.

\section{FIELD CANCERISATION, MULTIFOCAL DISEASE, AND SECOND MALIGNANCIES \\ Field cancerisation and second primary tumours}

The concept of "field cancerisation" was first introduced in 1953 by Slaughter $e t a l^{40}$ after noting the presence of multiple "independent" tumours and "abnormal epithelium" in the mucosa adjacent to HNSCC. In his now classic study, Slaughter et al ${ }^{40}$ described multiple carcinomas in $11.2 \%$ of 783 unselected cases of HNSCC. Slaughter postulated that "multicentric origin through a process of field cancerisation would seem to be an important factor in the persistence or recurrence of epidermoid carcinoma following therapy". In its classical interpretation, the concept of "field cancerisation" refers to large areas of the aerodigestive tract mucosa affected by long term exposure to carcinogens, resulting in genetically altered fields in which multifocal carcinomas can develop because of independent genetic events. Many techniques, including chromosome $\mathrm{X}$ inactivation, microsatellite analysis, and p53 mutational analysis have confirmed the presence of genetic alterations in the mucosa adjacent to primary HNSCCs, thus providing a genetic explanation for Slaughter's concept of field cancerisation, ${ }^{91-46}$ but in contrast to Slaughter's original assertion, these studies strongly suggest that most tumours arising in these abnormal fields are clonally related and originate from a common preneoplastic progenitor. It has been hypothesised that these multiple tumours are caused by the migration of transformed cells through the upper aerodigestive tract mucosa, either by intraepithelial migration or by saliva (micrometastases). The transformed cells have a survival advantage and eventually displace or replace the surrounding mucosa through a process known as "clonal expansion".9 ${ }^{46}$

The frequency of genetically abnormal fields in mucosa surrounding HNSCC is difficult to ascertain as most studies addressing this problem have been retrospective, but there is evidence suggesting that it is significantly high. Tabor et al ${ }^{42}$ found genetically altered fields in the non-neoplastic mucosa of $36 \%$ of unselected patients with HNSCC. More importantly, in $70 \%$ of these patients, the altered field extended to the surgical margins. Brennan et al ${ }^{47}$ also detected p53 mutations in 13 of 25 patients (52\%) who appeared to have complete tumour resection on the basis of microscopically negative surgical margins; in a different study Tabor et a ${ }^{41}$ found p53 mutations in $60 \%$ of the specimen margins of 10 patients with multiple HNSCC. The size of the abnormal field is difficult to estimate but it can be large and surely varies considerably from patient to patient. Tabor $e t \mathrm{al}^{41}$ reported six clonally related tumours separated by $3-6 \mathrm{~cm}$, Worsham et $a l^{48}$ reported two clonally related synchronous carcinomas from the anterior floor of the mouth and pyriform sinus, and Califano et $a l^{49}$ described a patient with multiple squamous cell carcinomas from the hypopharynx and distal oesophagus showing similar allelic loss separated by $40 \mathrm{~cm}$.

Although there is substantial molecular and genetic evidence supporting the concept of field cancerisation, debate remains over the clonal relation of preneoplastic and neoplastic lesions developing in these fields and their mode of spread. ${ }^{6051}$ Establishing the clonal relation of multiple tumours in the same patient is not always easy or straightforward. Unrelated tumours may lose the same allele by chance alone, and related tumours may show differing allelotypes owing to the accumulation of new alterations during tumour progression. Tabor et $a l^{42}$ demonstrated this conundrum when comparing the genetic alterations between the "field" and the tumours in 28 patients with HNSCC, and found that in only $20 \%$ of cases did the tumour and the "field" show similar alterations. In the remaining group, $60 \%$ of tumours showed additional losses indicative of genetic progression whereas in $40 \%$, the "field" showed alterations not present in the index tumour. ${ }^{42}$ In another study, these group of investigators showed discordant genetic alterations between the primary tumour and the corresponding lymph node metastasis in nine of 20 patients (45\%). Therefore, similar patterns of $\mathrm{LOH}$ with statistical analysis, identical breakpoints, shared microsatellite shifts, and similar p53 mutations have been recommended as evidence of common clonal origin. ${ }^{10}{ }^{51}$ Using a combination of current techniques it appears that approximately $60-70 \%$ of carcinomas arising in a field originate from a common precursor clone $e^{41} 465253$ whereas the remaining appear to represent "true" multiple primary tumours..$^{452} 54$

Braakhuis et $a l^{61}$ have proposed a new classification of secondary HNSCCs arising after treatment of an oral or oropharyngeal carcinoma based on the degree of clonal relation (fig 2). They defined field cancerisation as mucosa with "the presence of one or more areas consisting of epithelial cells that have genetic alterations. A field lesion (or field) has a monoclonal origin, and does not show invasive growth or metastatic behavior". ${ }^{\prime}$ These investigators proposed that tumours with similar genetic profile should be classified as "recurrence" or a metastasis depending on whether the second lesion occurs in the same or a distant anatomical site. If the individual tumours show different genetic alterations, the secondary lesion should be regarded a "true" second primary tumour (SPT). The third group consists of lesions with a common genetic origin but which diverge in later stages; therefore some show similar allelic imbalances and mutations but others show different genotypes. This latter group is classified as "second field tumours" (SFTs)..$^{51}$

\section{Molecular pathology of HNSCC and second primary tumours in lung and oesophagus}

Approximately 5\% of patients with HNSCC develop lung metastases. Given the morphological similarities, the distinction of a primary lung carcinoma from a solitary lung metastasis in a patient with HNSCC cannot be made reliably on histopathological grounds in most cases. To address this problem, Leong et al ${ }^{55}$ examined the status of chromosomes $3 p$ and $9 p$ in 16 patients with paired resected primary HNSCC and solitary lung carcinomas. Ten of the 16 patients $(63 \%)$ showed concordant allelic loss at all loci, consistent with a common clonal origin and strongly supporting the conclusion that the pulmonary tumours represented solitary metastases. Three additional samples had different allelic 


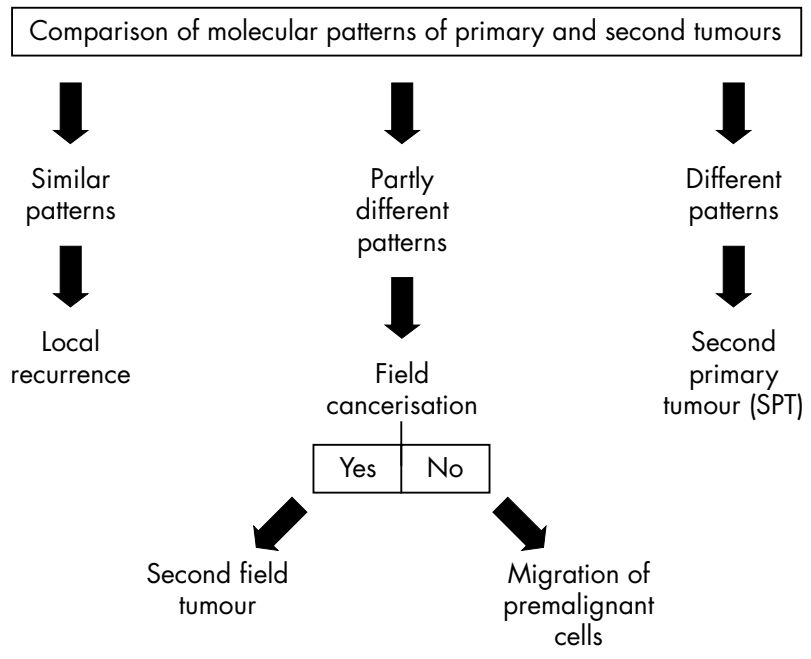

Figure 2 Proposed classification by Braakhuis et a ${ }^{51}$ of second tumours after a primary HNSCC.

losses consistent with an independent tumour origin, suggesting that the lung lesions were second primary tumours. These results suggest that the majority of solitary lung squamous carcinomas in patients with HNSCC are in fact metastases rather than second primaries, with a smaller number representing second primary tumours. The clonal relation of HNSCC and second "primary" oesophageal squamous cell carcinoma has been investigated by Califano et a ${ }^{49}$ using microsatellite markers located on chromosomal arms $3 p, 9 p$, and $17 p$ in paired tumours of the head and neck and oesophagus. In 14 cases (83\%) the paired tumours had discordant patterns of allelic loss, whereas only two (13\%) had identical genetic alterations. Thus most oesophageal carcinomas in patients with HNSSC appear to arise as independent neoplasms with only a small percentage being clonally related.

\section{Detection of minimal disease in surgical margins} Approximately $3.9-32 \%$ of patients with HNSCC develop local recurrences despite the presence of microscopically negative margins. ${ }^{56-58}$ Several studies have investigated the presence and clinical implications of molecular alterations in seemingly tumour-free mucosa in the surgical margins of patients undergoing curative surgery for HNSCC. ${ }^{47960}$ Detection of genotypically abnormal cells at the surgical margins of resection may be helpful in identifying individuals with a heightened risk of local recurrences after complete surgical resection. In a seminal study addressing this problem, Brennan et al ${ }^{47}$ demonstrated p53 mutations in 13 of 25 patients (52\%) who appeared to have complete tumour resection on the basis of microscopically negative surgical margins. Five of these 13 patients developed local recurrences whereas none of the 12 patients without mutations had recurrences of their tumour. In a study by van Houten et al ${ }^{59}$ 50 of 76 patients (66\%) showed p53 mutations in one or more of the surgical margins regarded as "negative" by conventional histopathology. Nine of the patients with p53 mutations developed local recurrences and four developed regional disease. In the group without p53 mutations, there were no local failures and only one patient developed regional disease. $^{59}$ These investigators found that no other clinicopathological index was predictive of development of local or regional failure. Molecular studies are also helpful in detecting small foci of abnormal mucosa overlooked by conventional histopathological assessment. In a study by van der Toom et al, ${ }^{60}$ a combination of p53 immunostaining and in situ hybridisation for chromosomes 1 and 7 demonstrated the presence of abnormal cells in 11 of 20 margins (55\%) diagnosed as tumour-free in their initial microscopic assessment. After examination of the p53 stains and ISH findings, atypical clusters of 10 to 20 cells that had been diagnosed as normal or hyperplastic became evident. All these cases were upgraded to low grade dysplasia with no case being upgraded to high grade dysplasia or carcinoma.

Data from several studies by Nathan et al ${ }^{61-63}$ have suggested some prognostic value for overexpression of the proto-oncogene eIF4E in histologically negative margins of HNSCC; eIF4E is a eukaryotic protein synthesis initiation factor increased in almost all HNSCC cases. ${ }^{63}$ Using immunohistochemistry, Nathan ${ }^{61}{ }^{62}$ showed statistically significant differences in local recurrence rates and disease-free intervals between eIF4E positive and eIF4E negative margins; patients with eIF4E-positive margins had a 6.5-fold risk of developing local recurrences. eIF4E was reported to be a more sensitive prognostic indicator for local recurrences than p53 immunohistochemistry.

\section{Gene profiling of head and neck squamous cell carcinoma}

The development of high throughput, hybridisation based methods such as cDNA and oligonucleotide microarrays allows the simultaneous analysis of gene expression alterations in thousands of genes in HNSCC. ${ }^{64-71}$ These studies have used a variety of experimental designs, tumour types, array platforms, and statistical tools, making direct comparisons of results difficult; however, the potential biological and clinical implications of gene expression signatures of HNSCC in tumour classification, prognosis, and treatment are enormous.

The molecular heterogeneity and complexities of subcellular abnormalities in HNSCC have been clearly highlighted by expression studies; however, most of these studies have been small and need independent confirmation in larger groups of patients. In a study of 17 patients with HNSCC, Belbin et $a l^{67}$ identified 375 genes that discriminated between two genotypic subtypes of HNSCC. Patients in group I were younger and had more early stage and paradoxically, poorly differentiated tumours with lower prevalence of nodal metastasis than those in group II; however, $38 \%$ of patients in group I died of their cancer whereas none of those in group II died as a result of their cancer after a median follow up period of four years. El-Naggar et al ${ }^{66}$ analysed 12 matched pairs of normal squamous mucosa and tumour samples from six conventional HNSCC and six variants HNSCC. Parallel expression analysis of 8055 genes showed 26 differentially expressed genes between normal mucosa and tumour specimens. Most of the genes with differential expression were associated with cell differentiation and proliferation. Some of the highly expressed genes in all the tumours included keratin 5, small proline-rich protein $1 \mathrm{~B}$ (cornifin), S-100 calcium binding protein A8, and keratin 14. Cluster analysis also showed some differences in the overall pattern of expression of certain keratins between conventional HNSCC and variant HNSCC. Conventional HNSCC showed a striking increase in keratins 5 and 14, while none of the variants HNSCC showed changes in those genes. Cornifin was highly expressed in most of the conventional HNSCC but not in the variants. Sarcomatoid and verrucous carcinomas had a pattern of gene expression that was closer to each other than to papillary and basaloid carcinomas. In a different study using a combination of cDNA substraction and microarray analysis, Villaret et $a l^{69}$ found overexpression of 13 genes in HNSCC compared with normal mucosa. These genes included keratin 6, keratin 16, cell adhesion related molecules (plakophilin, laminin, and connexin 26), metalloproteinases (stromelysin-2), p53 regulated elements (14-3-3 

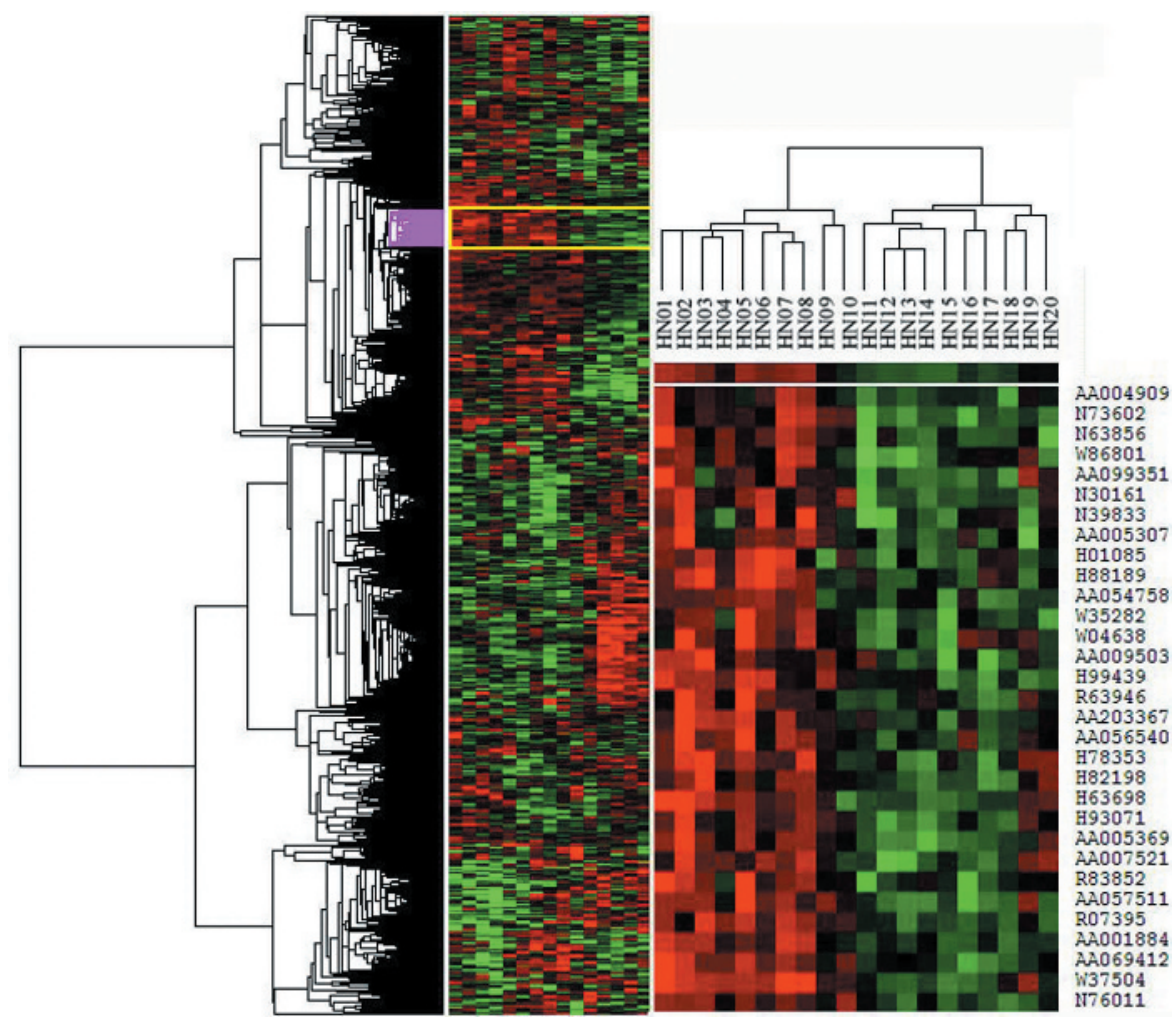

Figure 3 Unsupervised hierarchical cluster analysis of gene expression of 20 oral squamous cell carcinomas on the basis of 1482 genes. Clustering of gene expression is shown on the left, where each row represents one sequence. Genes are shown on the right besides each row. The dendogram shows two groups of tumours. Cluster 1 (left) shows patients with lymph node metastasis compared with cluster 2 (right), which contains patients with early disease stage and no lymph node metastases. Red represents overexpression, green represents underexpression, and black represents no change in gene expression in comparison with a baseline sample (universal RNA, control). (Courtesy of Dr Suzanne Kamel-Reid, Toronto, Canada.)

sigma protein), and a S-100 calcium binding protein (CaN19). In a study of 60 HNSCCs, Chung et al ${ }^{72}$ identified four distinct subtypes of HNSCC, based on gene expression. These subtypes included tumours with an EGFR pathway signature, a mesenchymal enriched subtype, a normal epithelium-like subtype, and a subtype with high levels of antioxidant enzymes. The first or EGFR pathway subtype was characterised by overexpression of the genes for transforming growth factor $\alpha(\mathrm{TGF} \alpha)$, fibroblast growth factor binding protein (FGF-BP), MMK6, bullous pemphigoid antigen 1, Pcadherin, laminin $\gamma 2$, and collagen XVII- $\alpha$, in addition to genes involved in desmosome function (desmoglein 3, desmocollin 2) and keratin 14. The mesenchymal enriched subtype showed high expression of vimentin, syndecan 2 , lysyl-oxidase, and four collagen subunits. The normal epithelium-like subtype had the highest expression of microsomal glutathione s-transferase 2 and keratins 15 and 4. The last group included tumours with high expression of glutathione s-transferase M3, thioredoxin reductase 1 , and glutathione peroxidase 2 among others. The median follow up period in this study was short, but the investigators reported no significant association between these tumour groups and clinical findings. ${ }^{72}$

Another line of investigation suggests that gene profiling by cDNA microarrays is capable of identifying upregulated and downregulated genes correlated with tumour recurrences and lymph node metastases (fig 3). ${ }^{73}{ }^{74}$ In a study of 20 previously untreated patients, Schmalbach et al ${ }^{73}$ found significant differential expression of 101 genes between metastatic and non-metastatic oral and pharyngeal carcinomas. The differential profile included genes related to extracellular matrix, cell adhesion and motility, inflammation, and protease inhibition. Collagen type $11 \alpha-1$ (COL1lAl) and tissue inhibitor of metalloproteinase 1 (TIMP-1) were upregulated in metastatic tumours, whereas serine protease inhibitor-2 (SERPINB2) was downregulated. In a study of 16 oral squamous cell carcinomas, O'Donnell et al ${ }^{75}$ concluded that metastatic tumours could be differentiated from nonmetastatic tumours on the basis of their differential expression of 116 genes. COL2 upregulation was one of the genes associated a "metastatic signature". ${ }^{75}$ Ginos et al ${ }^{76}$ described a "recurrent disease signature" seen in tumours with overexpression of genes implicated in stromal invasion (snail homologue 2, met proto-oncogene), RAS signalling (r-ras homologue), cell surface/extracellular matrix interactions (collagen type IV $\alpha_{5}$ and $\alpha_{6}$, laminin $\gamma 2, \alpha_{3}, \beta_{3}$; integrin $\alpha_{3}$, $\left.\alpha_{6}, \beta_{4}, \beta_{6}\right)$ and angiogenesis. All seven patients whose tumours expressed the "recurrent disease signature" failed treatment within 12 months of resection of their primary lesion. ${ }^{76}$ Using a different technology and data analysis, Warner et $a l^{74}$ found that claudin-l (CLDN1) overexpression was significantly correlated with lymph node metastases and advanced tumour stage. Roepman and associates ${ }^{77}$ have recently reported a predictor of lymph node metastases of HNSCC based on the differential expression of 102 genes. Among the predictor genes were genes encoding extracellular matrix components, genes involved in cell adhesion, cell death genes, cell growth and maintenance genes, and genes encoding proteins involved in the degradation of the extracellular matrix. The predictor had an initial overall accuracy of $86 \%$ and correctly identified 19 of 22 cases on a subsequent validation set. Interestingly, long term storage of tumour samples affected the predictor performance negatively.

\section{HUMAN PAPILLOMAVIRUS AND HNSCC}

The causal link between human papillomavirus (HPV) and a subset of HNSCC cases has become established in recent years. ${ }^{78-80}$ HPV DNA has been identified in approximately $15 \%$ of HNSCC cases. $^{80-83}$ The most commonly detected HPV in HNSCC is HPV-16, which has been demonstrated in 90-95\% of all HPV positive HNSCC cases, followed by HPV-18, HPV33, and HPV-33. ${ }^{83-86}$ The prevalence of HPV DNA in HNSCC varies according to tumour site. The most common location of HPV associated HNSCC (HPV-HNSCC) is the oropharynx. 

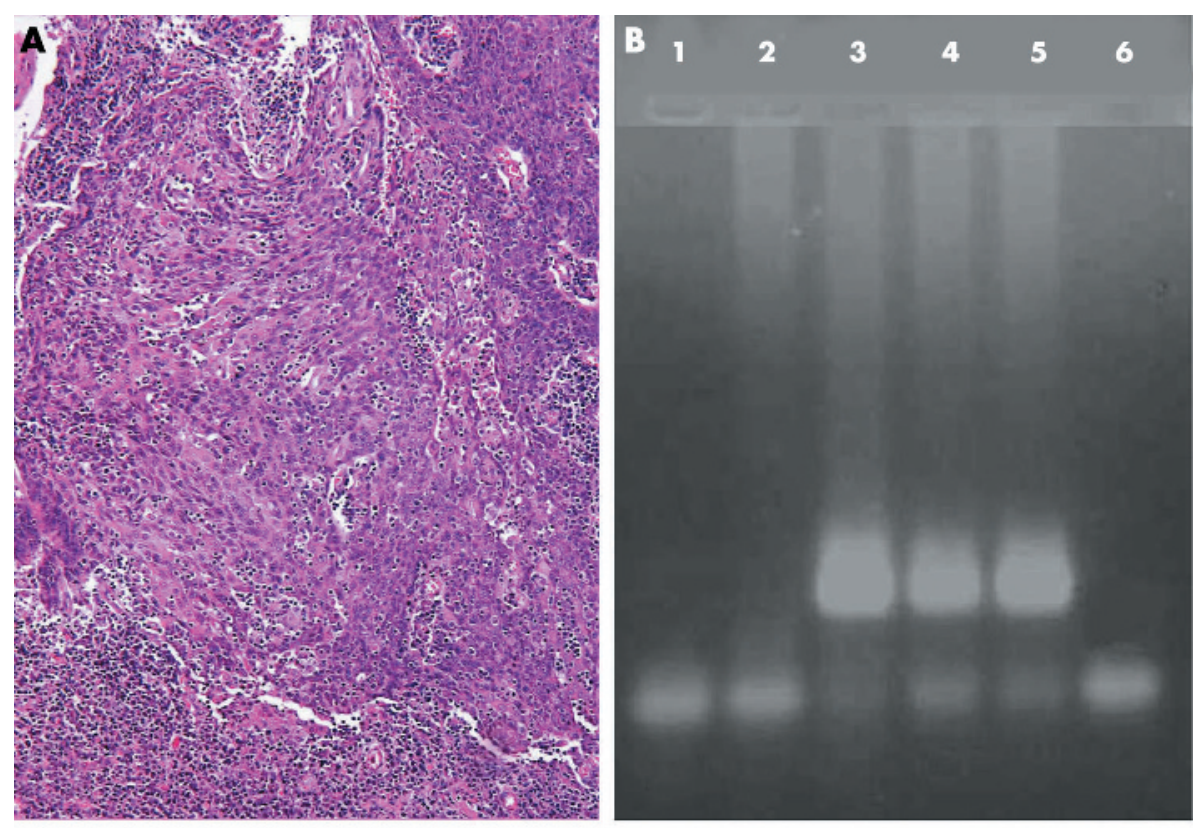

Figure 4 Poorly differentiated squamous cell carcinoma of tonsil with no evidence of keratinisation (A). Polymerase chain reaction products of DNA extracted from formalin fixed, paraffin embedded tissue show the presence of HPV-16 DNA in lanes 3 to 5 (B). Strong immunoexpression of p16 in same cases (C) with markedly reduced expression of $\mathrm{Rb}$ protein (D).
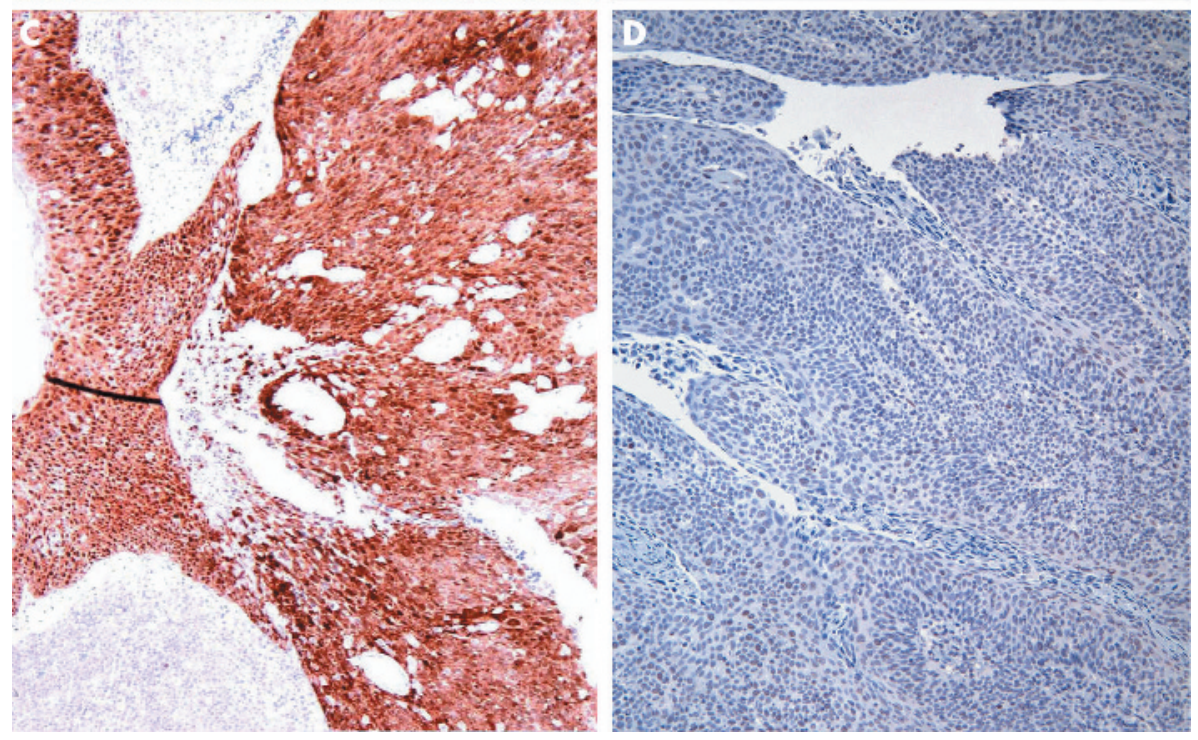

HPV is especially common in carcinomas of the lingual and palatine tonsils, where its reported prevalence has ranged from $45 \%$ to $67 \%{ }^{80-83} 8788$ A detailed review of HPV infections and tonsillar carcinoma by Syrjänen has been published recently in this journal. ${ }^{89}$ HPV DNA has been found less often in squamous cell carcinomas of the oral cavity (12-18\%), tongue (12\%), hypopharynx (13-25\%), and larynx (3-7\%). ${ }^{82}$ Epidemiological and case matched studies have also shown that individuals who are seropositive for HPV-16 are at an increased risk for the development of oral or oropharyngeal squamous cell carcinomas. ${ }^{79} 8690$ After adjustment for age, sex, and serum cotinine levels, HPV-16 seropositive individuals have a greater risk of development of oral squamous cell carcinomas (odds ratio 2.8) and oropharyngeal squamous cell carcinomas (odds ratio 14.4) than seronegative individuals. ${ }^{79}$

There is a growing body of evidence suggesting that oropharyngeal HPV-HNSCC is a distinctive clinicopathological and molecular entity. ${ }^{82}{ }^{91}$ The risk factors for HPV-HNSCC appear to be different from those of non-HPV HNSCC. Although not universally reported, patients with HPVHNSCC are less likely to have a history of tobacco use, are more likely to be diagnosed at a younger age, and have a higher frequency of cervical lymph node metastases at presentation. They are also more likely to report a high lifetime number of heterosexual partners, young age at first intercourse, and a history of orogenital sex..$^{85} 8690$ Most tonsillar HPV-HNSSCs are associated with poorly differentiated, non-keratinising, basaloid morphology, wild-type p53 status, $\mathrm{pl} 6^{\mathrm{INK} 4 \mathrm{~A}}$ overexpression, and decreased cyclin Dl and $\mathrm{Rb}$ expression..$^{80}{ }^{92-96}$ High risk oncogenic HPVs such as HPV16 and HPV-18 encode two oncoproteins, E6 and E7, which induce cellular transformation and dysregulation of cell cycle control. E7 interacts and induces proteolytic degradation of $\mathrm{pRb}$ and other RB related "pocket" proteins, whereas E6 inactivates $\mathrm{p} 53$ by accelerating its ubiquitin mediated proteolysis. ${ }^{97}$ In accordance with the oncogenic properties of E6, approximately $90 \%$ of HPV-HNSCCs have wild type p53 and lack immunohistochemical overexpression of p53. ${ }^{809999}$ Given the ability of E7 to target $\mathrm{Rb}$ for degradation, $\mathrm{Rb}$ expression is decreased in HPV-HNSCC (fig 4). ${ }^{92}{ }^{100}$ Absence of pl6 mutations and overexpression of p16 ${ }^{\text {INK4A }}$ are also molecular hallmarks of HPV-HNSCC..$^{99-102}$ It has been suggested that overexpression of pl6 may be used as a surrogate marker to identify HPV-HNSCC, and when 
detected in lymph node metastases is a reliable way to establish an oropharyngeal origin..$^{96} 103$

There is strong evidence suggesting that patients with HPV-HNSCC have a more favourable prognosis with lower disease specific mortality than those with HPV-negative HNSCC. ${ }^{80} 84104105$ Gillison et $^{8 l^{80}}$ reported a 59\% reduction in risk of death from cancer in patients with HPV-HNSCC compared with HPV-negative HNSCC. The detection of HPV in HNSCC has potentially significant therapeutic implications, given the development of vaccines targeting HPV oncogenic proteins E6 and E7 for the prevention of HPV related malignancies. ${ }^{106}$

\section{MOLECULAR BIOLOGY OF SQUAMOUS CELL CARCINOMA IN YOUNG INDIVIDUALS}

Unlike their counterparts in older patients, HNSCC affecting young individuals show an increased incidence in females with no known risk factors, and occur more frequently in the oral cavity and hypopharynx. ${ }^{107-109}$ The influence of young age on survival has been controversial, with some investigators reporting improved clinical outcome in comparison with older patients, ${ }^{110}$ whereas most have found no differences on survival. ${ }^{107} 109$ Such clinicopathological differences suggest that these tumours represent a biologically distinct entity; however, only a few studies have focused on the molecular biology of HNSCC arising in young individuals. In a study comparing "young" and "old" patients, Wang et al ${ }^{108}$ found a significant greater frequency of microsatellite instability in the young group $(88 \% v 36 \%)$. Microsatellite instability was also detected at a higher frequency in tongue $(71 \%)$ than in laryngeal cancers $(23 \%)$. The mechanism of microsatellite instability in these tumours was unclear as there were no mutations or promoter methylation of mismatch repair (MMR) genes.

With the possible exception of Fanconi anaemia, the role of HPV in the pathogenesis of HNSCC of young individuals appears to be related to anatomical site of the tumour rather than to age on its own. Sisk and collaborators ${ }^{111}$ compared the prevalence of HPV between "young" and "old" patients but found no significant differences in the presence of HPV DNA in these two groups. El-Mofty and $\mathrm{Lu}^{93}$ investigated the prevalence of HPV-16 in 33 HNSCCs from young patients. They found a high prevalence of HPV-16 in tonsillar carcinomas $(91 \%)$. No HPV was found in any of the oral carcinomas and only two of seven laryngeal carcinomas showed HPV DNA.

Fanconi anaemia is an autosomal recessive genomic instability syndrome associated with congenital abnormalities, bone marrow failure, and a predisposition to the development of acute myeloid leukaemia and other solid cancers. ${ }^{112}$ The relative risk of developing HNSCC in individuals with Fanconi anaemia is 700 times greater than in the general population, the median age at diagnosis of their carcinoma being 26 years. ${ }^{113} 114$ The risk is greater in patients undergoing haematopoietic stem cell transplantation and in those with acute and chronic graft-versus-host diseases. ${ }^{115}$ The molecular mechanisms involved in Fanconi anaemia associated head and neck carcinogenesis are not completely understood; however, Kutler et al ${ }^{116}$ found HPV-16 DNA in a high proportion of HNSCCs affecting individuals with this condition. As is the case with other HPV related HNSCCs, these tumours lacked p53 mutations. These findings support a significant role for HPV in the pathogenesis of HNSCCs arising in the context of Fanconi anaemia. ${ }^{106}$ The role played by the Fanconi anaemia/BRCA pathway in sporadic HNSCCs, particularly in young individuals with no known risk factors, has not been widely explored; however, in a recent study, Marsit et al ${ }^{100}$ demonstrated promoter methylation of the FANCF gene in $15 \%$ of sporadic HNSCC cases.

\section{CONCLUSION}

More traditional molecular studies and genomic arrays will afford us the opportunity for molecular classification of HNSCCs, which will ultimately provide additional insights into HNSCC and possibly new targeted molecular treatments. Despite all these exciting advances, the most effective and cost-efficient tools in reducing the worldwide morbidity and mortality caused by HNSCC are public health policies aimed at reducing or eliminating the use of tobacco products.

Concerns have been recently raised regarding the validity of the results and conclusions regarded in references 37, 38 and 39.

\section{Authors' affiliations}

B Perez-Ordoñez, Department of Pathology, University Health Network, and Department of Pathobiology and Laboratory Medicine, University of Toronto, Toronto, Ontario, Canada

M Beauchemin, Department of Pathology, Hôpital du Saint-Sacrement, Centre Hospitalier afflilié Universitaire de Québec, Quebec, Canada R C K Jordan, Department of Orofacial Sciences and Department of Pathology, University of California, San Francisco, California, USA

\section{REFERENCES}

1 Stewart BW, Kleihues P. World Cancer Report. Geneva: International Agency for Research on Cancer, 2003:232-6.

2 Canadian Cancer Society. Canadian Cancer Statistics 2005 (www.ncic.cancer.ca).

3 Carvalho AL, Nishimoto IN, Califano JA, et al. Trends in incidence and prognosis for head and neck cancer in the United States: a site-specific analysis of the SEER database. Int J Cancer 2005;114:806-16.

4 Forastiere A, Koch W, Trotti A, et al. Head and neck cancer. N Engl J Med 2001;345:1890-900.

5 Williams HK. Molecular pathogenesis of oral squamous carcinoma. Mol Pathol 2000;53:165-72.

6 Braakhuis BJ, Tabor MP, Kummer JA, et al. A genetic explanation of Slaughter's concept of field cancerization: evidence and clinical implications. Cancer Res 2003:63:1727-30.

7 Grandis JR, Pietenpol JA, Greenberger JS, et al. Head and neck cancer: meeting summary and research opportunities. Cancer Res 2004;64:8126-9.

8 Nawroz H, van der Riet P, Hruban RH, et al. Allelotype of head and neck squamous cell carcinoma. Cancer Res 1994;54:1152-5.

9 Califano J, van der RP, Westra W, et al. Genetic progression model for head and neck cancer: implications for field cancerization. Cancer Res 1996;56:2488-92.

10 Califano J, Westra WH, Meininger G, et al. Genetic progression and clonal relationship of recurrent premalignant head and neck lesions. Clin Cancer Res 2000;6:347-52.

11 van der Riet $\mathbf{P}, \mathrm{Nawroz} H$, Hruban $\mathrm{RH}$, et al. Frequent loss of chromosome 9 p21-22 early in head and neck cancer progression. Cancer Res 1994;54:1156-8.

12 Mao L, Lee JS, Fan YH, et al. Frequent microsatellite alterations at chromosomes $9 p 21$ and $3 p 14$ in oral premalignant lesions and their value in cancer risk assessment. Nat Med 1996;2:682-5.

13 Rosin MP, Cheng X, Poh C, et al. Use of allelic loss to predict malignant risk for low-grade oral epithelial dysplasia. Clin Cancer Res 2000;6:357-62.

14 Reed AL, Califano J, Cairns P, et al. High frequency of p16 (CDKN2/MTS-1/ (NK4A) inactivation in head and neck squamous cell carcinoma. Cancer Res 1996;56:3630-3

15 Garnis C, Baldwin C, Zhang L, et al. Use of complete coverage array comparative genomic hybridization to define copy number alterations on chromosome $3 p$ in oral squamous cell carcinomas. Cancer Res 2003;63:8582-5.

16 Hogg RP, Honorio S, Martinez A, et al. Frequent $3 p$ allele loss and epigenetic inactivation of the RASSF1A tumour suppressor gene from region 3 p21.3 in head and neck squamous cell carcinoma. Eur J Cancer 2002;38:1585-92.

17 Rowley H, Jones A, Spandidos D, et al. Definition of a tumor suppressor gene locus on the short arm of chromosome 3 in squamous cell carcinoma of the head and neck by means of microsatellite markers. Arch Otolaryngol Head Neck Surg 1996;122:497-501.

18 Masayesva BG, Ha P, Garrett-Mayer E, et al. Gene expression alterations over large chromosomal regions in cancers include multiple genes unrelated to malignant progression. Proc Natl Acad Sci USA 2004;101:8715-20.

19 Kisielewski AE, Xiao GH, Liu SC, et al. Analysis of the FHIT gene and its product in squamous cell carcinomas of the head and neck. Oncogene 1998; 17:83-91.

20 Mao L, Fan YH, Lotan R, et al. Frequent abnormalities of FHIT, a candidate tumor suppressor gene, in head and neck cancer cell lines. Cancer Res 1996:56:51 28-31. 
21 Dong SM, Sun DI, Benoit NE, et al. Epigenetic inactivation of RASSF1A in head and neck cancer. Clin Cancer Res 2003;9:3635-40.

22 van Houten VM, Tabor MP, van den Brekel MW, et al. Mutated p53 as a molecular marker for the diagnosis of head and neck cancer. J Pathol 2002;198:476-86.

23 Boyle JO, Hakim J, Koch W, et al. The incidence of p53 mutations increases with progression of head and neck cancer. Cancer Res 1993;53:4477-80.

24 Shahnavaz SA, Regezi JA, Bradley G, et al. p53 gene mutations in sequential oral epithelial dysplasias and squamous cell carcinomas. J Pathol 2000;190:417-22.

25 Meredith SD, Levine PA, Burns JA, et al. Chromosome 11q13 amplification in head and neck squamous cell carcinoma. Association with poor prognosis. Arch Otolaryngol Head Neck Surg 1995;121:790-4.

26 Michalides R, van Veelen N, Hart A, et al. Overexpression of Cyclin D1 correlates with recurrence in a group of forty-seven operable squamous cell carcinomas of the head and neck. Cancer Research 1995;55:975-8.

27 Maruya S, Issa JP, Weber RS, et al. Differential methylation status of tumorassociated genes in head and neck squamous carcinoma: incidence and potential implications. Clin Cancer Res 2004;10:3825-30.

28 Rousseau A, Lim MS, Lin Z, et al. Frequent cyclin D1 gene amplification and protein overexpression in oral epithelial dysplasias. Oral Oncol 2001;37:268-75

29 El-Naggar AK, Hurr K, Huff V, et al. Microsatellite instability in preinvasive head and neck squamous carcinoma. Am J Pathol 1996;148:2067-72.

$30 \mathrm{Ha}$ PK, Pilkington TA, Westra WH, et al. Progression of microsatellite instability from premalignant lesions to tumors of the head and neck. Int J Cancer 2002; 102:615-17.

31 Ha PK, Benoit NE, Yochem R, et al. A transcriptional progression model for head and neck cancer. Clin Cancer Res 2003;9:3058-64.

32 Hellquist H, Lundgren J, Olofsson J. Hyperplasia, keratosis, dysplasia and carcinoma in situ of the vocal cords. Follow-up study. Clin Otolaryngol 1982;7:11-27.

33 Silverman S Jr, Gorsky M, Lozada F. Oral leukoplakia and malignant transformation. A follow-up study of 257 patients. Cancer 1984;53:563-8.

34 Brothwell DJ, Lewis DW, Bradley G, et al. Observer agreement in the grading of oral epithelial dysplasia. Community Dent Oral Epidemiol 2003;31:300-5.

35 Lee JJ, Hong WK, Hittelman WN, et al. Predicting cancer development in oral leukoplakia: ten years of translational research. Clin Cancer Res 2000;6: 1702-10

36 Zhang $L$, Williams $M$, Poh $C F$, et al. Tolvidine blue staining identifies highrisk primary oral premalignant lesions with poor outcome. Cancer Res 2005;65:8017-21

37 Sudbo J, Kildal W, Risberg B, et al. DNA content as a prognostic marker in patients with oral leukoplakia. N Engl J Med 2001;344:1270-8

38 Sudbo J, Ried T, Bryne M, et al. Abnormal DNA content predicts the occurrence of carcinomas in non-dysplastic oral white patches. Oral Oncol $2001 ; 37: 558-65$

39 Sudbo J, Lippman SM, Lee JJ, et al. The influence of resection and aneuploidy on mortality in oral leukoplakia. N Engl J Med 2004;350:1405-13.

40 Slaughter DP, Southwick HW. "Field cancerization" in oral stratified squamous epithelium. Clinical implications of multicentric origin. Cancer 1953;6:963-8.

41 Tabor MP, Brakenhoff RH, Ruijter-Schippers HJ, et al. Multiple head and neck fumors frequently originate from a single preneoplastic lesion. Am J Pathol 2002;161:1051-60.

42 Tabor MP, Brakenhoff RH, van Houten VM, et al. Persistence of genetically altered fields in head and neck cancer patients: biological and clinical implications. Clin Cancer Res 2001;7:1523-32.

43 Tabor MP, Brakenhoff RH, Ruijter-Schippers HJ, et al. Genetically altered fields as origin of locally recurrent head and neck cancer: a retrospective study. Clin Cancer Res 2004; 10:3607-13.

44 Lydiatt WM, Anderson PE, Bazzana T, et al. Molecular support for field cancerization in the head and neck. Cancer 1998;82:1376-80.

45 van Oijen MG, Leppers Vd Straat FG, Tilanus MG, et al. The origins of multiple squamous cell carcinomas in the aerodigestive tract. Cancer 2000;88:884-93

46 Bedi GC, Westra WH, Gabrielson E, et al. Multiple head and neck tumors: evidence for a common clonal origin. Cancer Res 1996;56:2484-7.

47 Brennan JA, Mao L, Hruban RH, et al. Molecular assessment of histopathological staging in squamous-cell carcinoma of the head and neck. N Engl J Med 1995;332:429-35.

48 Worsham MJ, Wolman SR, Carey TE, et al. Common clonal origin of synchronous primary head and neck squamous cell carcinomas: analysis by tumor karyotypes and fluorescence in situ hybridization. Hum Pathol 1995;26:251-61

49 Califano J, Leong PL, Koch WM, et al. Second esophageal tumors in patients with head and neck squamous cell carcinoma: an assessment of clonal relationships. Clin Cancer Res 1999;5:1862-7.

50 van Oijen MG, Slootweg PJ. Oral field cancerization: carcinogen-induced independent events or micrometastatic deposits? Cancer Epidemiol Biomarkers Prev 2000;9:249-56.

51 Braakhuis BJ, Tabor MP, Leemans CR, et al. Second primary tumors and field cancerization in oral and oropharyngeal cancer: molecular techniques provide new insights and definitions. Head Neck 2002;24:198-206.

52 Scholes AG, Woolgar JA, Boyle MA, et al. Synchronous oral carcinomas: independent or common clonal origin? Cancer Res 1998:58:2003-6.

53 Partridge M, Pateromichelakis S, Phillips E, et al. Profiling clonality and progression in multiple premalignant and malignant oral lesions identifies a subgroup of cases with a distinct presentation of squamous cell carcinoma. Clin Cancer Res 2001;7:1860-6.
54 Jang SJ, Chiba I, Hirai A, et al. Multiple oral squamous epithelial lesions: are they genetically related? Oncogene $2001 ; 20: 2235-42$.

55 Leong PP, Rezai B, Koch WM, et al. Distinguishing second primary tumors from lung metastases in patients with head and neck squamous cell carcinoma. J Natl Cancer Inst 1998;90:972-7.

56 Slootweg PJ, Hordijk GJ, Schade Y, et al. Treatment failure and margin status in head and neck cancer. A critical view on the potential value of molecular pathology. Oral Oncol 2002;38:500-3.

57 Looser KG, Shah JP, Strong EW. The significance of "positive" margins in surgically resected epidermoid carcinomas. Head Neck Surg 1978;1:107-11.

58 Chen TY, Emrich $\sqcup$, Driscoll DL. The clinical significance of pathological findings in surgically resected margins of the primary tumor in head and neck carcinoma. Int J Radiat Oncol Biol Phys 1987; 13:833-7

59 van Houten VM, Leemans CR, Kummer JA, et al. Molecular diagnosis of surgical margins and local recurrence in head and neck cancer patients: a prospective study. Clin Cancer Res 2004;10:3614-20.

60 van der Toorn PP, Veltman JA, Bot FJ, et al. Mapping of resection margins of oral cancer for p53 overexpression and chromosome instability to detect residual (pre)malignant cells. J Pathol 2001;193:66-72.

61 Nathan CA, Amirghahri N, Rice C, et al. Molecular analysis of surgical margins in head and neck squamous cell carcinoma patients. Laryngoscope 2002; 112:2129-40

62 Nathan CA, Sanders K, Abreo FW, et al. Correlation of p53 and the protooncogene elF4E in larynx cancers: prognostic implications. Cancer Res $2000 \cdot 60 \cdot 3599-604$

63 Nathan CA, Franklin S, Abreo FW, et al. Analysis of surgical margins with the molecular marker elF4E: a prognostic factor in patients with head and neck cancer. J Clin Oncol 1999;17:2909-14.

64 Alevizos I, Mahadevappa M, Zhang X, et al. Oral cancer in vivo gene expression profiling assisted by laser capture microdissection and microarray analysis. Oncogene $2001 ; 20: 6196-204$.

65 Leethanakul C, Patel V, Gillespie J, et al. Distinct pattern of expression of differentiation and growth-related genes in squamous cell carcinomas of the head and neck revealed by the use of laser capture microdissection and cDNA arrays. Oncogene 2000;19:3220-4.

66 el Naggar AK, Kim HW, Clayman GL, et al. Differential expression profiling of head and neck squamous carcinoma: significance in their phenotypic and biological classification. Oncogene 2002;21:8206-19.

67 Belbin TJ, Singh B, Barber I, et al. Molecular classification of head and neck squamous cell carcinoma using cDNA microarrays. Cancer Res 2002;62:1184-90.

68 Mendez E, Cheng C, Farwell DG, et al. Transcriptional expression profiles of oral squamous cell carcinomas. Cancer 2002;95:1482-94.

69 Villaret DB, Wang T, Dillon D, et al. Identification of genes overexpressed in head and neck squamous cell carcinoma using a combination of complementary DNA subtraction and microarray analysis. Laryngoscope 2000;110:374-81.

70 Choi P, Chen C. Genetic expression profiles and biologic pathway alterations in head and neck squamous cell carcinoma. Cancer 2005; 104:1113-28.

71 Baker H, Patel V, Molinolo AA, et al. Proteome-wide analysis of head and neck squamous cell carcinomas using laser-capture microdissection and tandem mass spectrometry. Oral Oncol 2005;41:183-99.

72 Chung $\mathrm{CH}$, Parker JS, Karaca G, et al. Molecular classification of head and neck squamous cell carcinomas using patterns of gene expression. Cancer Cell 2004:5:489-500.

73 Schmalbach CE, Chepeha DB, Giordano TJ, et al. Molecular profiling and the identification of genes associated with metastatic oral cavity/pharynx squamous cell carcinoma. Arch Otolaryngol Head Neck Surg 2004; 130:295-302.

74 Warner GC, Reis PP, Jurisica I, et al. Molecular classification of oral cancer by CDNA microarrays identifies overexpressed genes correlated with nodal metastasis. Int J Cancer 2004;110:857-68.

75 O'Donnell RK, Kupferman M, Wei SJ, et al. Gene expression signature predicts lymphatic metastasis in squamous cell carcinoma of the oral cavity. Oncogene 2005;24:1244-51.

76 Ginos MA, Page GP, Michalowicz BS, et al. Identification of a gene expression signature associated with recurrent disease in squamous cell carcinoma of the head and neck. Cancer Res 2004:64:55-63.

77 Roepman P, Wessels LF, Kettelarij N, et al. An expression profile for diagnosis of lymph node metastases from primary head and neck squamous cell carcinomas. Nat Genet 2005;37:182-6.

78 Herrero R. Human papillomavirus and cancer of the upper aerodigestive tract. J Natl Cancer Inst Monogr, 2003;47-51..

79 Mork J, Lie AK, Glattre E, et al. Human papillomavirus infection as a risk factor for squamous-cell carcinoma of the head and neck. N Engl J Med 2001;344:1125-31.

80 Gillison ML, Koch WM, Capone RB, et al. Evidence for a causal association between human papillomavirus and a subset of head and neck cancers. J Natl Cancer Inst 2000;92:709-20.

81 Fouret $\mathrm{P}$, Martin F, Flahault $A$, et al. Human papillomavirus infection in the malignant and premalignant head and neck epithelium. Diagn Mol Pathol $1995 ; 4: 122-7$

82 Paz IB, Cook N, Odom-Maryon T, et al. Human papillomavirus (HPV) in head and neck cancer. An association of HPV 16 with squamous cell carcinoma of Waldeyer's tonsillar ring. Cancer 1997:79:595-604.

83 Ringstrom E, Peters E, Hasegawa M, et al. Human papillomavirus type 16 and squamous cell carcinoma of the head and neck. Clin Cancer Res 2002:8:3187-92 
84 Schwartz SR, Yueh B, McDougall JK, et al. Human papillomavirus infection and survival in oral squamous cell cancer: a population-based study. Otolaryngol Head Neck Surg 2001;125:1-9.

85 Smith EM, Ritchie JM, Summersgill KF, et al. Age, sexual behavior and human papillomavirus infection in oral cavity and oropharyngeal cancers. Int J Cancer 2004; 108:766-72.

86 Herrero R, Castellsague X, Pawlita M, et al. Human papillomavirus and oral cancer: the International Agency for Research on Cancer multicenter study. J Natl Cancer Inst 2003;95:1772-83.

87 Klussmann JP, Weissenborn SJ, Wieland U, et al. Human papillomaviruspositive tonsillar carcinomas: a different tumor entity? Med Microbiol Immunol (Berl) 2003;192:129-32.

88 Strome SE, Savva A, Brissett AE, et al. Squamous cell carcinoma of the tonsils: a molecular analysis of HPV associations. Clin Cancer Res 2002;8:1093-100.

89 Syrianen S. HPV infections and tonsillar carcinoma. J Clin Pathol 2004:57:449-55.

90 Dahlstrom KR, Adler-Storthz K, Etzel CJ, et al. Human papillomavirus type 16 infection and squamous cell carcinoma of the head and neck in neversmokers: a matched pair analysis. Clin Cancer Res 2003;9:2620-6.

91 Gillison ML. Human papillomavirus-associated head and neck cancer is a distinct epidemiologic, clinical, and molecular entity. Semin Oncol 2004;31:744-54.

92 Wilczynski SP, Lin BT, Xie Y, et al. Detection of human papillomavirus DNA and oncoprotein overexpression are associated with distinct morphological patterns of tonsillar squamous cell carcinoma. Am J Pathol patterns of tonsillar squ
1998;152:145-56.

93 el Mofty SK, Lu DW. Prevalence of human papillomavirus type 16 DNA in squamous cell carcinoma of the palatine tonsil, and not the oral cavity, in young patients: a distinct clinicopathologic and molecular disease entity. Am J Surg Pathol 2003;27:1463-70.

94 Poetsch M, Lorenz G, Bankau A, et al. Basaloid in contrast to nonbasaloid head and neck squamous cell carcinomas display aberrations especially in cell cycle control genes. Head Neck 2003;25:904-10.

95 Li W, Thompson CH, Cossart YE, et al. The expression of key cell cycle markers and presence of human papillomavirus in squamous cell carcinoma of the tonsil. Head Neck 2004;26:1-9.

96 Begum S, Gillison ML, Ansari-Lari MA, et al. Detection of human papillomavirus in cervical lymph nodes: a highly effective strategy for localizing site of tumor origin. Clin Cancer Res 2003;9:6469-75.

97 Munger K, Howley PM. Human papillomavirus immortalization and transformation functions. Virus Res 2002;89:213-28.

98 Dai M, Clifford GM, Le Calvez F, et al. Human Papillomavirus Type 16 and TP53 Mutation in Oral Cancer: Matched Analysis of the IARC Multicenter Study. Cancer Res 2004:64:468-71.

99 Hafkamp HC, Speel EJ, Haesevoets A, et al. A subset of head and neck squamous cell carcinomas exhibits integration of HPV 16/18 DNA and overexpression of p16INK4A and p53 in the absence of mutations in p53 exons 5-8. Int J Cancer 2003;107:394-400
100 Wiest T, Schwarz E, Enders C, et al. Involvement of intact HPV16 E6/E7 gene expression in head and neck cancers with unaltered p53 status and perturbed pRb cell cycle control. Oncogene 2002;21:1510-17.

101 Olshan AF, Weissler MC, Pei H, et al. Alterations of the pl6 gene in head and neck cancer: frequency and association with p53, PRAD-1 and HPV. Oncogene 1997; 14:811-18.

102 Klussmann JP, Gultekin E, Weissenborn SJ, et al. Expression of pl6 protein identifies a distinct entity of tonsillar carcinomas associated with human papillomavirus. Am J Pathol 2003;162:747-53.

103 Begum S, Cao D, Gillison M, et al. Tissue distribution of human papillomavirus 16 DNA integration in patients with tonsillar carcinoma. Clin Cancer Res 2005;11:5694-9.

104 Li W, Thompson CH, O'Brien CJ, et al. Human papillomavirus positivity predicts favourable outcome for squamous carcinoma of the tonsil. Int J Cancer 2003; 106:553-8.

105 Ritchie JM, Smith EM, Summersgill KF, et al. Human papillomavirus infection as a prognostic factor in carcinomas of the oral cavity and oropharynx. Int J Cancer 2003; 104:336-44.

106 Devaraj K, Gillison ML, Wu TC. Development of HPV vaccines for HPVassociated head and neck squamous cell carcinoma. Crit Rev Oral Biol Med 2003; 14:345-62.

107 Verschuur HP, Irish JC, O'Sullivan B, et al. A matched control study of treatment outcome in young patients with squamous cell carcinoma of the head and neck. Laryngoscope 1999;109:249-58.

108 Wang Y, Irish J, MacMillan C, et al. High frequency of microsatellite instability in young patients with head-and-neck squamous-cell carcinoma: lack of involvement of the mismatch repair genes hMLH1 AND hMSH2. Int J Cancer 2001;93:353-60.

109 Pitman KT, Johnson JT, Wagner RL, et al. Cancer of the tongue in patients less than forty. Head Neck 2000;22:297-302.

110 Annertz K, Anderson H, Biorklund A, et al. Incidence and survival of squamous cell carcinoma of the tongue in Scandinavia, with special reference to young adults. Int J Cancer 2002;101:95-9.

111 Sisk EA, Bradford CR, Jacob A, et al. Human papillomavirus infection in "young" versus "old" patients with squamous cell carcinoma of the head and neck. Head Neck 2000;22:649-57.

112 D'Andrea AD, Grompe M. The Fanconi anaemia/BRCA pathway. Nat Rev Cancer 2003:3:23-34

113 Kutler DI, Auerbach AD, Satagopan J, et al. High incidence of head and neck squamous cell carcinoma in patients with Fanconi anemia. Arch Otolaryngol Head Neck Surg 2003;129:106-12.

114 Alter BP, Joenje $H$, Oostra AB, et al. Fanconi anemia: adult head and neck cancer and hematopoietic mosaicism. Arch Otolaryngol Head Neck Surg 2005;131:635-9.

115 Rosenberg PS, Socie G, Alter BP, et al. Risk of head and neck squamous cell cancer and death in patients with Fanconi anemia who did and did not receive transplants. Blood 2005; 105:67-73.

116 Kutler DI, Wreesmann VB, Goberdhan A, et al. Human papillomavirus DNA and $\mathrm{p} 53$ polymorphisms in squamous cell carcinomas from Fanconi anemia patients. J Natl Cancer Inst 2003;95:1718-21. 